\title{
O cuidado com a saúde na era da ciência e da técnica: o que é a saúde, afinal?
}

\author{
Healthcare in the era of science and technology: \\ after all, what is health?
}

\author{
André Luís de Oliveira Mendonça \\ Pós-doutorando, Instituto de Medicina Social/Universidade do Estado do Rio de Janeiro. \\ alomendonca@gmail.com
}

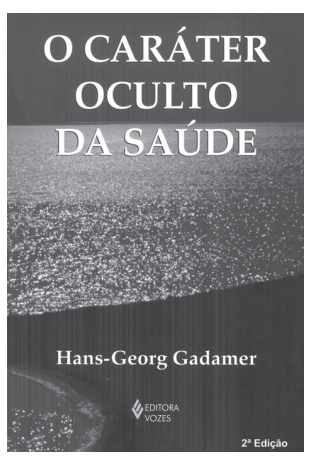

GADAMER, Hans-Georg. O caráter oculto da saúde. Petrópolis: Vozes. 2006. $176 \mathrm{p}$.
$\mathrm{D}$ esde que veio a lume sua obra Verdade e método (1997 [1960]), Hans-Georg Gadamer tornou-se um dos filósofos mais insignes da segunda metade do século XX, ao lado de Michel Foucault, Jürgen Habermas e Richard Rorty, entre outros. Como o subtítulo, Traços fundamentais de uma hermenêutica filosófica, permite inferir, o objetivo norteador da referida obra consistiu em advogar a tese em prol de uma hermenêutica como filosofia, ou de uma filosofia como hermenêutica. Herdando uma tradição que remonta a Friedrich Schleiermacher (1768-1834), tendo sido levada adiante por Wilhelm Dilthey (18331911), pode-se afirmar que Gadamer renovou profundamente os pressupostos, a natureza e o escopo da hermenêutica, a começar justamente por seu projeto de torná-la uma filosofia, procurando aplicá-la reflexivamente a si mesma também, e não mais, como seus pais fundadores almejaram, de fazer dela uma ciência da interpretação e da compreensão (uma espécie de epistemologia voltada para a fundamentação das ciências humanas ou das humanidades em geral). Influenciado, notavelmente, pelo diálogo socrático-platônico, pelo conceito aristotélico de phrônesis e pela analítica existencial/ontologia fundamental de Martin Heidegger, como também pelo conceito de "historicidade" hegeliano e de "mundo da vida" de Edmund Husserl, Gadamer foi responsável por instituir uma significação ontológica e universal para a hermenêutica, no sentido de uma postura de diálogo e abertura em face do mundo e das pessoas, partindo do reconhecimento de que somos finitos e de que, portanto, nosso conhecimento é sempre incompleto e provisório. Como argumentou Rorty (1994), quiçá a grande contribuição da hermenêutica gadameriana residiu em ter mostrado, de modo edificante, como é possível tornar "familiar" aquilo que nos aparece como "estranho" à primeira vista, graças à busca incessante em direção ao encontro com a alteridade do outro. É nesse sentido que, para Gadamer, a hermenêutica não era um mero método ou técnica de interpretar ou compreender textos, mas sim uma postura existencial frente a todas as facetas do humano, posto que a vida é repleta de dimensões e acontecimentos que escapam ao nosso controle e ao nosso entendimento imediatos. 
Com a sua hermenêutica filosófica, Gadamer repensou, de forma singular e original, os velhos temas da história da filosofia, sobretudo da dita "tradição humanística". Mais precisamente, ele deixou marcas indeléveis no debate gravitando em torno das três principais esferas da cultura humana que se teriam autonomizado com o advento do projeto da modernidade, a saber: ética, arte e ciência. Especificamente sobre a ciência, há uma interpretação difundida de acordo com a qual Gadamer fora um autor anticientífico, uma vez que ele teria chamado a atenção para os limites da racionalidade monológica engendrada pela ciência moderna e defendido a superioridade das humanidades frente ao "tecnicismo reducionista". Faz-se oportuno, entretanto, ressaltar que Gadamer tão somente criticou uma ciência desprovida de responsabilidade social, e não a prática científica enquanto tal, como se pode depreender, por exemplo, da leitura do seu livro A razão na época da ciência (1983). Seu projeto filosófico pode ser compreendido como uma tentativa heroica de resgate do interesse pelo humano em sua integralidade: deveríamos valorizar, simetricamente, o aspecto estético-expressivo, ético-valorativo e epistêmico-cognitivo da nossa existência; e, além disso, talvez sua meta precípua fosse salvaguardar a dimensão humana mais relegada pela modernidade ao limbo da história: nosso pendor quase natural para as questões ontológicas e metafísicas (é bom lembrar que as questões sobre o Ser em Gadamer são colocadas levando em consideração a nossa historicidade). Não bastasse sua visão enciclopédica sobre as diversas áreas do saber, Gadamer foi decisivo em pelo menos mais duas searas pelas quais também enveredou grande parte dos seus contemporâneos: as discussões travadas sobre a história e a linguagem. Pertinentes ainda são suas críticas ao objetivismo histórico (Gadamer, 2006), bem como sua concepção de linguagem como diálogo hermenêutico (daí, aliás, seu pensamento ser também denominado "dialética dialógica", devido ao papel central que o diálogo autêntico desempenha).

Coerente com sua hermenêutica universal - não se trata de um método de interpretação exclusivo para as artes e humanidades visando lhes extrair sentido dos aspectos que são aparentemente destituídos de compreensibilidade à primeira leitura, mas, na realidade, ela seria uma postura prudente e recomendável em toda e qualquer situação em que a aplicação de regras formais simplesmente não funciona -, Gadamer fez incursões sobre praticamente todos os campos do conhecimento, incluindo a medicina. O livro O caráter oculto da saúde é justamente uma feliz reunião de artigos e conferências de Gadamer - realizados em "conjunturas especiais", como ele mesmo afirma na primeira linha do prefácio -, cobrindo um período de 25 anos (de 1965 a 1990), em que ele trata de questões referentes ao cuidado com a saúde no contexto da ciência e da técnica. A tese geral do pensamento gadameriano que permeia o livro consiste na assunção segundo a qual a ciência (medicina como ciência) em que pese sua tarefa imprescindível e insubstituível - não é capaz de dar conta, sozinha, de todos os fatores que englobam o humano, enquanto a tese específica sobre a questão da saúde (a mais original do livro; expressa também no título) é aquela que afirma ser a própria saúde, e não a doença, o acontecimento verdadeiramente misterioso (miraculoso) a ser perscrutado. Em diálogo constante com os pensadores originários (nomeadamente, Platão e Aristóteles) e com alusão indireta aos seus contemporâneos (ouvem-se ecos, por exemplo, das ideias de Canguilhem e Foucault), Gadamer examina diversas facetas do cuidado com a saúde, sobre as quais discorro a passos largos, a partir dos capítulos do livro per se (13 no total). 
O primeiro capítulo, "Teoria, técnica, prática", o mais extenso do livro, funciona estrategicamente para colocar a questão de fundo do autor: vivemos na era da ciência. Traçando uma distinção entre as concepções grega e moderna acerca da teoria, técnica e prática, Gadamer nos adverte sobre a necessidade de realizarmos uma espécie de desmitologização da "desmitologização": nem iconoclastia preconceituosa, nem crença supersticiosa na ciência moderna. A meu ver, ele traz à baila uma discussão incontornável: a relação (conflitante?) entre a ciência e as demais tradições e instituições da nossa sociedade, isto é, o choque entre a ciência e os valores do "mundo da vida". A pergunta sobre a qual Gadamer medita diz respeito aos problemas relativos à possibilidade real de a ciência fundamentar, plena e satisfatoriamente, a vida social em bases racionais. Sua resposta aponta para a direção de um paradoxo de difícil solução: "quanto mais racionais as formas de organização da vida são modeladas, tanto menos é praticada e ensinada a capacidade racional de julgamento", ou "quanto mais intensivamente a área de aplicação é racionalizada, mais falta o próprio exercício do juízo e, com isso, a experiência prática no seu verdadeiro sentido" (p.26). Esse paradoxo é atrelado a outra temática recorrente no livro: a especialização (sua questão norteadora parece ser o medo tanto do autoritarismo quanto do embotamento que o especialismo pode gerar). Ao longo do livro, Gadamer defende, com veemência, a necessidade de não abdicarmos da ideia de "totalidade", no sentido de uma visão integral do saber sobre o homem. Sua "utopia" é a de que o progresso científico e tecnológico seja acompanhado de um desenvolvimento de uma consciência sociopolítica mais ampla. Nesse sentido, as ciências humanas desempenhariam uma tarefa decisiva, uma vez que são capazes de nos suprir com uma ampla perspectiva atinente à diversidade de se poder ser "ser humano", como também são responsáveis por nos tornar conscientes de que toda e qualquer perspectiva está carregada de valores, o que implica, portanto, sempre uma normatividade, ainda que não declarada, mesmo no caso da ciência. De todo modo, de maneira interessante e autêntica, Gadamer conclama os cientistas naturais a reconhecer esses problemas como passíveis de ser pesquisados, embora não de forma totalmente "naturalizante" (experimental).

No segundo capítulo, "Apologia da arte de curar", o autor sustenta uma das teses centrais do livro: o papel preponderante da natureza na saúde. A marca da arte médica consiste no restabelecimento do "equilíbrio natural". A rigor, a genuína arte de curar consiste em tornar-se supérflua: "A arte médica se completa na retirada dela mesma e na liberação do outro" (p.51). A questão premente é saber a medida certa da intervenção médica (quando ela é "muito demais" ou "pouco demais", ou seja, encontra-se aqui subjacente o problema da medicalização). Outrossim, Gadamer ressalta uma dúvida constitutiva: quem é verdadeiramente responsável pelo sucesso ou pelo fracasso da cura em "situações normais" o médico ou a natureza?

"Sobre o problema da inteligência", terceiro capítulo do livro, apesar de aparentemente deslocado das questões gerais pertencentes ao campo da saúde, serve para Gadamer reafirmar sua tese primordial de que o ser humano deve ser pensado em sua totalidade. Contrapondo-se ao conceito formal de "inteligência como desempenho", predominante naquele momento, ele defende uma concepção de inteligência mais abrangente, de modo a impedir a instrumentalização da pessoa humana. Vale-se do exemplo da saúde mental 
justamente para mostrar como é preciso levar em consideração o estado da pessoa na sua integralidade.

Em "A experiência da morte", o quarto capítulo, Gadamer aborda o tema crucial da vida, que, segundo ele, teria sofrido uma grande transformação com o processo de secularização desencadeado com a modernidade e consolidado com o predomínio da racionalidade técnica da sociedade atual. Estaríamos vivendo sob a égide de uma desmitologização da morte (desmitologização da vida). Não obstante a suposta superação da conotação mística ou religiosa da morte e da vida, haveria um paradoxo persistente: o avanço tecnológico no prolongamento artificial da vida confronta-se com o limite do nosso "ser-capaz-de-fazer" relativo à morte. Em todo caso, permanece viva nossa tensão essencial entre a consciência acerca da nossa própria finitude e o impetuoso não querer saber que somos seres para a morte.

À procura de um equilíbrio entre a razão instrumental científica e os valores humanos, no quinto capítulo, "Experiência corporal e objetivabilidade", Gadamer remonta à arte de curar dos gregos para propor uma unidade entre corpo e alma, tendo em vista o homem integral. Nesse sentido, enfatiza os limites da ciência médica que se volta apenas para os aspectos biológicos (corporeidade instrumental), tomando o caso das doenças crônicas como o exemplo por meio do qual ficaria demonstrado, cabalmente, que outros fatores além dos aspectos meramente "biomédicos" atuam diretamente na saúde das pessoas.

Apesar de o título não aparentar, o sexto capítulo, "Entre natureza e arte", aborda uma questão relevante com relação à saúde. Como é frequente ao longo do livro, Gadamer retoma o significado grego de "arte" como techné: o saber e o ser-capaz-de-fazer que sabe. Ora, no caso específico da saúde, a tarefa do médico não consiste em saber fazer uma obra, mas, pura e simplesmente, restituir o doente ao seu "estado natural" e à unidade consigo mesmo. Essa ideia de o médico ser um simples auxiliar da natureza é recorrente no livro.

No sétimo capítulo, "Filosofia e medicina prática", Gadamer desenvolve um argumento que seria trivial se não fosse amiúde esquecido: a prática médica não se dá, como se pensa ser o caso na interface de teoria e técnica, como a mera aplicação de uma lei geral. Cada situação concreta possui sua singularidade ("o paciente é uma pessoa, e não um caso"). Daí os limites dos aparelhos tecnológicos de medição. Como, aliás, acontece em outros capítulos, Gadamer relembra o conceito de "medida" em Platão como aquilo que é "apropriado" (adequação moderada), de modo a superar a concepção meramente quantitativa de medição (qual seria a medida adequada da medicalização em cada situação concreta parece ser, mais uma vez, a questão subjacente). A dificuldade de se atentar para o "apropriado" nas clínicas modernas advém justamente da ausência do "olhar" e da "escuta". Também nesse capítulo, pela primeira vez de modo mais explícito, apresenta-se a tese que dá título ao livro: a saúde é algo que se subtrai ao exame; ela pertence ao "milagre do autoesquecimento". Por isso, a saúde não pode ser totalmente objetivada pela ciência médica. Essa tese reaparece no capítulo seguinte, intitulado justamente "Sobre o caráter oculto da saúde". Nas palavras de Gadamer, a verdadeira singularidade reside no milagre da saúde, e não na doença. A doença, e não a saúde, é que é algo aparentemente auto-objetivante. Eis o verdadeiro mistério: o caráter oculto da saúde, uma vez que não há possibilidade de medi-la; trata-se de um estado de adequação interna e de conformidade consigo próprio. Mas o que seria a saúde, afinal? "Ela é o ritmo da vida, um processo contínuo, no qual o equilíbrio sempre volta a se estabilizar" (p.119). 
Em "Autoridade e liberdade crítica", nono capítulo, Gadamer parte de uma espécie de antinomia da modernidade - a autoridade da ciência conflitaria com a liberdade crítica -, com o intuito de defender a legitimidade da autoridade do médico quando ela é embasada no seu ser-capaz-de-fazer, ou, para colocar em termos mais contemporâneos, na sua expertise. $\mathrm{Na}$ realidade, Gadamer propõe um entrelaçamento indissociável entre autoridade e liberdade crítica, sublinhando uma dupla exigência ética do exercício da autoridade de um especialista: autocrítica e autodisciplina. Autoridade autêntica consiste exatamente na liberdade crítica consigo mesmo, reconhecendo os próprios limites; abuso de autoridade seria não transmitir a outrem (no caso, o paciente) uma verdadeira libertação por meio de compreensão própria.

A despeito da originalidade do capítulo em que trata especificamente do caráter oculto da saúde, é no décimo capítulo, "Tratamento e diálogo", que Gadamer se vale do conceito central de sua filosofia - "diálogo" -, para pensar a questão do cuidado em saúde. Começando com uma análise filológica - frequente no livro e no seu pensamento - sobre a palavra "tratamento" (oriunda de "apalpar"), ele nos adverte que a ausência do tocar, do ouvir e do olhar concorrem para obstaculizar a arte genuína de curar. Seu diagnóstico é o de que o problema mais grave da medicina atual está na falta de diálogo entre médico e paciente. Consoante Gadamer, o diálogo já constitui, em si, "tratamento". Em virtude disso é que ele vai defender uma convergência entre diagnose, tratamento, diálogo e "colaboração do paciente". Isso sem esquecer obviamente de outra tese recorrente no livro: a cura é o pleno poder da natureza, e não do médico. Para ser mais preciso, é preciso ressalvar que Gadamer destaca a "dúbia" relação que nós devemos ter com a natureza: "Precisamente esta é a nossa natureza, ter de nos impor também perante a natureza, até onde podemos. Mas, com maior razão, é próprio à natureza humana manter-se - em todo o saber e ser-capaz-de-fazer - em harmonia com a natureza. Esta é a antiga sabedoria estoica" (p.144).

O $11^{\circ}$ capítulo, "Vida e alma", é o mais "filológico" de todos, no qual Gadamer recorre especialmente às concepções gregas dos filósofos originários para contrastar os seus significados de "vida" e "alma" com os dos modernos, a partir da presunção de que teria havido, por um lado, uma restrição dos sentidos antigos e, por outro, uma permanência subjacente às mudanças. Já o $12^{\circ}$ capítulo, "Angústias e medos", é o mais filosófico de todos. Partindo das reflexões de Heidegger sobre angústia - em cuja obra "angústia" é uma categoria existencial que permite o despertar acerca da pergunta pelo ser/nada, e não uma disposição de humor psicológica, tampouco uma categoria psiquiátrica -, Gadamer pretende mostrar que, além de não ser doença, a angústia e os medos fazem parte da nossa "natureza" como seres humanos. Nesse sentido, a nossa busca de segurança e controle na era da técnica e ciência, por mais legítima que for, não pode esquecer que ela jamais apagará nossos traços mais essenciais.

O último capítulo, "Hermenêutica e psiquiatria", como o título mesmo sugere, traça um paralelo entre as duas áreas. A rigor, hermenêutica e psiquiatria possuiriam uma preocupação em comum: o interesse nas grandes questões humanas. Ambas partem da premissa segundo a qual os conceitos de saúde e doença descrevem situações vitais que ultrapassam o nível do objetivável, uma vez que o ser humano é uma totalidade biopsicossocial.

Ainda que algumas das teses sustentadas por Gadamer no livro não constituam, propriamente, grande novidade para a saúde coletiva - dado que o próprio campo já se nutre do manancial hermenêutico, entre tantos outros referenciais teóricos das mais variadas tradições 
de pensamento, desde os seus primórdios -, penso que O caráter oculto da saúde é uma obra que deveria ser lida e relida sob inspiração do "espírito" da hermenêutica gadameriana, porquanto ela possui todos os ingredientes necessários para propiciar um diálogo franco e aberto entre todos aqueles envolvidos no cuidado com a saúde, desde "pacientes" (usuários do sistema de saúde) e médicos (pena que Gadamer não menciona os demais profissionais da saúde), até gestores e pesquisadores. Com efeito, não se trata de discutir apenas, como é mais usual, as questões referentes às doenças, senão perscrutar aquilo que, mesmo que continue sendo um "mistério", merece ser examinado com cuidado: o conceito de saúde; sem deixar de atentar, com o fito de tentar responder o que vem a ser "saúde", para o fato de que vivemos na era da ciência ou, no caso, da medicina pretensamente científica, bem como em um contexto social de medicalização da existência. Que ciência nós queremos? Que saúde nós queremos? Essas me parecem ser as questões prementes subjacentes ao belo livro de Gadamer.

\section{REFERÊNCIAS}

GADAMER, Hans-Georg.

O problema da consciência histórica. Rio de Janeiro: FGV Editora. 2006.

GADAMER, Hans-Georg.

Verdade e método: traços fundamentais de uma hermenêutica filosófica. Petrópolis: Vozes. 1997.
GADAMER, Hans-Georg.

A razão na época da ciência. Rio de Janeiro: Tempo Brasileiro. 1983.

RORTY, Richard.

A filosofia e o espelho da natureza. Rio de Janeiro: Relume-Dumará. 1994. 